\title{
A study of sustainable practices in the sustainability leadership of international contractors
}

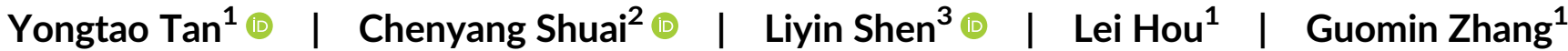

\author{
${ }^{1}$ School of Engineering, RMIT University, \\ Melbourne, Victoria, Australia \\ ${ }^{2}$ School for Environment and Sustainability, \\ University of Michigan, Ann Arbor, Michigan, \\ United States \\ ${ }^{3}$ School of Construction Management and Real \\ Estate, Chongqing University, Chongqing, \\ China

\section{Correspondence} \\ Yongtao Tan, School of Engineering, RMIT \\ University, GPO Box 2476, Melbourne, \\ Victoria 3001, Australia. \\ Email: yongtao.tan@rmit.edu.au \\ Funding information \\ Start-up fund for new staff of the School of \\ Engineering, RMIT University, Australia; School \\ of Engineering, RMIT University, Australia
}

\begin{abstract}
With an increasing global need for sustainable development, numerous world-leading construction corporations have devoted significant efforts to implementing sustainable practices. However, few previous studies have shared these valuable experiences in a systematic and quantitative way. RobecoSAM has published The Sustainability Yearbook annually since 2004, which lists the sustainability leaders in various industries, including the construction industry. Learning from those sustainability leaders in the construction industry can provide useful references for construction-related companies when developing their sustainable development strategies. Based on a comprehensive literature review, this paper identified 51 methods used for improving sustainability performance and 34 outcomes achieved via these methods. These methods and outcomes are used for coding the sustainable practices of sustainability leaders in the construction sector. Using the coding system, 133 annual sustainability reports issued by 22 sustainability leaders (The Sustainability Yearbook, RobecoSAM 2010-2016) in the construction sector were analyzed using content analysis. Social network analysis was then employed to identify the key adopted methods and achieved outcomes (KAMAO) of these leaders. The dynamic trend and regional analysis of KAMAO are also presented. These KAMAO findings provide valuable guidance for international contractors to develop a better understanding of the primary sustainable methods adopted by sustainability leaders in the construction sector and the top outcomes achieved by these leaders. The findings also provide a useful reference for international contractors to evaluate their current sustainability-related strategies and make improvements.
\end{abstract}

\section{KEYWORDS}

construction market, key adopted methods and achieved outcomes (KAMAO), social network analysis, sustainability leader, sustainable practice

\section{$1 \mid$ INTRODUCTION}

The construction industry is an important sector in promoting national socioeconomic development, in particular for developing countries (Chen, Shen, Song, Shi, \& Li, 2017; Guo, Ding, Zhang, Skibniewski, \& Liang, 2019; Tembo-Silungwe \& Khatleli, 2018). The construction industry is the pillar industry in China; it produces nearly $7 \%$ of the total Gross Domestic Product and provides over 30 million jobs (National Bureau of Statistics of China, 2015). Construction products have a significant influence on economic activities, human health, and social behavior, as well as on cultural identity and civic pride (Pearce, 2003). Nevertheless, they also have a number of negative impacts on the environment, such as extensive natural resources consumption, pollution, and greenhouse gas 
emissions. According to the U.S. Environmental Protection Agency (2009), the building sector is responsible for $72 \%$ of electricity consumption, $39 \%$ of energy consumption, $67 \%$ of solid waste, and $13 \%$ of potable water consumption. Research by Wu et al. (2018) has further pointed out that the construction industry is the second largest carbon emitter, accounting for approximately 33\% of global carbon emissions. Shi, Chen, and Shen (2017) stated that as a resource-intensive industry, the construction industry accounts for $30 \%$ of total energy consumption and consumes $70 \%$ of cement products and $25 \%$ of steel products in China.

Sustainable construction, defined as the creation and responsible maintenance of a healthy built environment based on resourceefficient and ecological principles, is proposed to mitigate these environmental and resource challenges in the construction sector (Burke, Parrish, \& El Asmar, 2018; Kibert, 1994). There are numerous benefits for contractors in implementing sustainable construction practices. Research by Tan, Shen, and Yao (2011) and Tan, Ochoa, Langston, and Shen (2015) has suggested that a sustainable construction strategy, such as good corporate governance of environmental and social issues, cannot only increase a company's shareholders' value but also enhance its valuable reputation. Robinson, Anumba, Carrillo, and Al-Ghassani (2006) concluded that competitive advantages can be achieved by implementing sustainable practices in construction, such as cost saving by reducing construction waste, better labor safety and health deriving from risk-reduction plans, and revenue gains from improved sustainability performance in the market. Given these benefits, it is crucial to establish sustainable practices in construction companies at the global level.

Over last decades, many large international construction corporations, such as Hyundai Engineering \& Construction Co. Ltd., Daelim Industrial Co. Ltd., ACCIONA, Fomento de Construcciones y Contratas, and Hochtief AG, have implemented various sustainable strategies (e.g., waste management, stakeholder engagement, ethical management, and the like) to improve their corporate sustainability performance. Although it has become important to share these successful sustainable practices among different construction companies, to the best of our knowledge, no relevant study has been carried out to examine the experiences and lessons of those sustainable practices in a quantitative and systematic way. Most existing studies focus on introducing the sustainable methods and outcomes (Ajayi et al., 2017; Jaafar et al., 2018; Sullivan, 2010). However, some basic questions have still not been adequately answered. For instance, what are the widely used methods and associated outcomes of the promotion of corporate sustainability performance at the global level? Among them, what key adopted methods and achieved outcomes (KAMAO) are necessary to being sustainability leaders? Are there any dynamic trends over time? Do they differ according to region? Thus, there is a need to systematically and quantitatively learn about and study the practices of sustainable construction. In this paper, 51 methods and 34 outcomes for promoting sustainable construction were identified based on a comprehensive literature review. Data on 133 annual sustainable reports from 22 world-leading construction corporations were collected and analyzed to answer these questions related to sharing sustainable construction practices.

\section{2 | LITERATURE REVIEW OF THE METHODS AND OUTCOMES OF CORPORATE SUSTAINABILITY}

Previous studies have focused on identifying the effective practices of cooperate sustainability under four dimensions, including governance, economic, social, and environment, which are regarded as the four pillars of sustainability assessment (Shen, Ochoa, Shah, \& Zhang, 2011). For the governance dimension, Jerónimo Silvestre, Antunes, Amaro, and Leal Filho (2015) identified "management system certification," such as the International Organization for Standardization 14001, Occupational Health and Safety Management Systems 18001, and Account Ability 1000 , as an effective method to promote the sustainability performance of 85 companies. Based on a comprehensive literature review, Linnenluecke and Griffiths (2010) proposed the sustainable "corporate culture with shared values" method, which enables enhanced coordination and increased motivation and goal alignment among organizational members. Research by Robinson et al. (2006) underlined the importance of the "knowledge management" (i.e., creating and sharing knowledge) method to strengthen an organization's learning performance.

In the economic field, Lo and Sheu (2007) introduced the sustainable "business portfolio optimization" method to identify attractive markets and opportunities, which can help organizations adjust their sales strategies and which in due course creates economic growth. Rao and Holt (2005) suggested that the "supply chain management" method has the ability to enhance corporate sustainability performance, especially by improving economic performance such as cost saving. Sherwin, Medal, and Lapp (2016) used a "proactive cost management" strategy to examine and compare the cost of each potential plan in advance in order to reduce the cost of a project and increase its profit.

As for the social perspective, the sustainable "social contribution" method, such as donations for disabled individuals on social welfare, local employment generation, and investments in other areas (e.g., building houses, parks, libraries, and schools), was proposed by Arrive and Feng (2018), who found that it can enhance a company's reputation and competitiveness. The study by den Hond, de Bakker, and Doh (2015) proposed that corporations use the "cooperation with non-governmental organizations (NGOs)" method, whereby environmental NGOs and business-oriented international NGOs respond to social and political pressures in their competitive environment to bolster their legitimacy and reputation and to anticipate and forestall negative actions by stakeholders. Jenkins, Bhanugopan, and Lockhart (2016) noted that "work-life balance" is a sustainable method, as it has substantial benefits not only for individual workers but also for the organization as a whole; for example, it can reduce absenteeism and illness rates and employee stress and can increase the company's productivity and profitability. 
With regard to the environmental dimension, Boiral and HerasSaizarbitoria (2017) recommended the "protection of biodiversity" method, involving wetlands, water, species, and forests, to help a company meet its regulation requirements and protect its reputation, which in turn increases its revenue. Research by Hellweg, and i Canals, L.M. (2014) introduced the sustainable "implementation of life-cycle assessment" strategy to help firms benchmark and optimize the environmental performance of their products and to help authorities design policies for sustainable consumption and production. Kristina, Ahmad, and Pratama (2014) proposed the effective "waste management" method, which involves enhancing recycling, reusing, and reducing (3R) to minimize environmental pollution and which uses organic and inorganic waste as a resource.

Based on our comprehensive literature review, a list of 51 widely used methods under four dimensions of corporate sustainability is presented in Table A1.

Similarly, a list of 33 outcomes of corporate sustainability is presented in Table B1. As opposed to methods being classified under four dimensions, outcomes are not classified. Completing this work is a challenge, as one method could achieve multiple outcomes and different methods could lead to the same outcome. Take the outcome of "company reputation improved" as an example: Three different methods, including "social contribution" (Arrive \& Feng, 2018), "promoting entrepreneurship" (Bierwerth, Schwens, Isidor, \& Kabst, 2015), and "climate change response" (Lee, Park, \& Klassen, 2015), could increase corporate reputation. Nevertheless, these methods belong under three different dimensions: social, governance, and environment. Therefore, it is difficult to classify this outcome under any of these dimensions.

\section{3 | RESEARCH METHODS}

To identify the KAMAO for promoting the sustainability performance of construction corporations, the content analysis and social network approaches were used in this research.

\subsection{Content analysis}

Content analysis was used to extract useful information from the collected annual sustainability reports. Content analysis was first proposed by Berelson as a research tool to study documents and uncover patterns in communication in a systematical way (Berelson, 1952). It can be used to analyze large-scale data with relevant analytic software. Human coding can also be used to supplement information extraction and is applicable to small-scale data (Tan, Xu, Jiao, Ochoa, \& Shen, 2017).

Five procedures use content analysis (Tan et al., 2017). First, research questions or hypotheses should be proposed. In this research, the research questions involve identifying the KAMAO of sustainable construction practices. Second, research samples should be collected. A total of 133 annual sustainability reports from 22 sustainability leaders in the construction sector were collected. Third, the categories for coding should be defined. The coding for sustainable methods and outcomes is presented in Appendices $A$ and B. Fourth, the content should be coded in detail. In this study, the human coding method is used for information extraction with reference to Appendices A and B. Fifth, extracted data should be analyzed. A social network analysis (SNA) tool is used to identify the KAMAO for promoting the sustainability performance of construction corporations.

\section{2 | Social network analysis}

SNA is an analytical method used to study social structures by means of network and graph theory. The network comprises various nodes (e.g., people, organizations within the network) and links (relationships among the nodes). Initially, SNA was used for solving social and psychological problems. In recent years, the principle behind this method has been extended to identify key elements and factors within a complex network (Fritsch \& Kauffeld-Monz, 2010; Loughead et al., 2016; Tan et al., 2017). The degree of centrality is used to measure the importance of different nodes in the network, whereby important nodes can be identified (Tan et al., 2017). For sustainable construction practices, one outcome can be achieved by using many methods, and one method can contribute to various outcomes. The adopted methods and achieved outcomes identified from sustainable practices comprise a complex network, making SNA a suitable tool to analyze its relations.

\section{3 | Data collection}

The major source of the data is from RobecoSAM's Sustainability Yearbook. RobecoSAM, a world-famous investment company that focuses primarily on global sustainability investing, provides asset management, sustainability assessments, impact analysis and investing, and benchmarking services. RobecoSAM publishes the Dow Jones Sustainability Indices and The Sustainability Yearbook to rank the sustainability of global companies. Within each industry, the company with the highest score is termed a sector leader and the company with the largest improvement is termed an industry mover. The sustainability leaders within each industry will receive three awards: gold class (within 1\% of the sector leader's score), silver class (within 1-5\% of the sector leader's score), and bronze class (within $5-10 \%$ of the sector leader's score; Tan et al., 2015). Based on the aims of the present research, the sustainability leaders in the heavy construction sector were selected for this study. Lastly, 22 international construction companies were identified based on the Sustainability Yearbook 2010-2016, as shown in Table C1. A total of 133 annual sustainability reports from 2010-2016 were obtained from the 22 international contractors' official websites. The data retrieved from the sustainability yearbooks and reports were used for content analysis and SNA. 


\section{4 | DATA EXTRACTION AND ANALYSIS}

\subsection{Overview of the practices in the reports}

The adopted methods and achieved outcomes in the annual sustainability reports were identified and coded by systematically reviewing all the reports. The methods adopted in the reports are ranked by their frequencies, as shown in Figure 1.

It can be seen from Figure 1 that there are significant differences in frequency among methods. For instance, the environmental method "sustainable and efficient resource and material use (MEn6)" is the most widely used method, with a frequency of 132 , which indicates that this method has been mentioned in nearly all of the reports. On the other hand, the economic method "minimizing bureaucracy (MEc1)" is found only once in all 133 reports. This is primarily because the method is usually used in state-owned companies or organizations (Berkowitz, Ma, \& Nishioka, 2017). Nevertheless, as most of these 22 companies (70\%) are privately owned, it is therefore understandable that very few of them use this method. The top 10 methods are the following: sustainable and efficient resource, energy, and material use (MEn6), health \& safety management (MS10), stakeholder engagement (MG3), concern with customer satisfaction (MEc5), waste management (MEn7), eco-friendly technologies (MEn3), climate change response (MEn2), quality management (MEc4), ethical management (MS1), materiality analysis (MG4), risk management (MEc3), and social contribution (MS13). Actually, there are 12 methods, as the last three methods have the same frequency of 103 . These top 10 methods are used for SNA. Similarly, 34 outcomes are ranked by frequency and shown in Figure 2.

There are also significant differences among outcomes. For instance, the outcome of environmental impacts reduced (O13) ranked first, with a frequency of 131 , implying that most reports achieved this outcome. This is reasonable, as most environmental methods are ranked high, such as MEn6 (top 1), MEn7 (top 5), MEn2 (top 6), and MEn33 (top 7), and these methods can help reduce environmental impacts (O13). Outcome $\mathrm{O} 11$ was only mentioned once in the reports, the outcome of implementing the MEc1 method. In addition, as seen in Figure 1, it is easy to note that the average frequency of each outcome is much higher than that of each method. This is mainly due to one method leading to various outcomes, and therefore, outcomes could be easily counted. The top 10 outcomes are the following: environmental impact reduced (013), employee creativity, motivation and efficiency improved (O28), company reputation improved (O25), safe and pleasant working environment created (031), steady business growth (07), loyal customers and reorders enhanced (O30), uncertainties reduced (O6), support from governments and NGOs (O34), employee loyalty enhanced (O29), energy and resources saving (014), lower waste generation (O16), technological capabilities enhanced (O23), and satisfaction and support of stakeholders (O26). These top 10 methods are used to conduct further SNA.

\section{2 | KAMAO identification for promoting overall sustainability performance}

The KAMAO were identified in this research using SNA. As mentioned above, the top 10 frequently adopted methods and achieved outcomes were selected to conduct an SNA. The adjacency matrices among the top 10 methods and top 10 outcomes were established based on the co-occurrence frequency between methods and outcomes (Tan et al., 2017). For example, the adjacency matrix is shown in

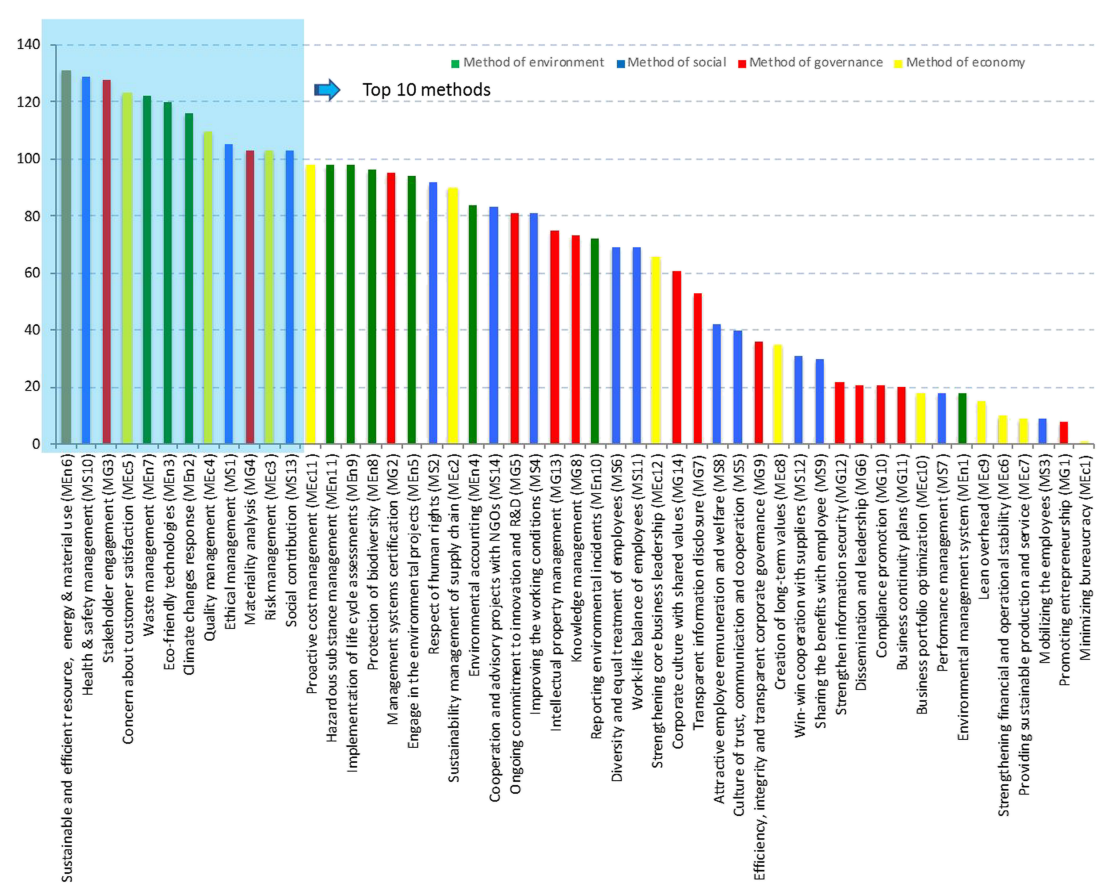

FIGURE 1 Ranking of adopted methods by the 22 sustainability leaders in the construction sector [Colour figure can be viewed at wileyonlinelibrary.com] 
FIGURE 2 Ranking of achieved outcomes by the 22 sustainability leaders in the construction sector [Colour figure can be viewed at wileyonlinelibrary.com]

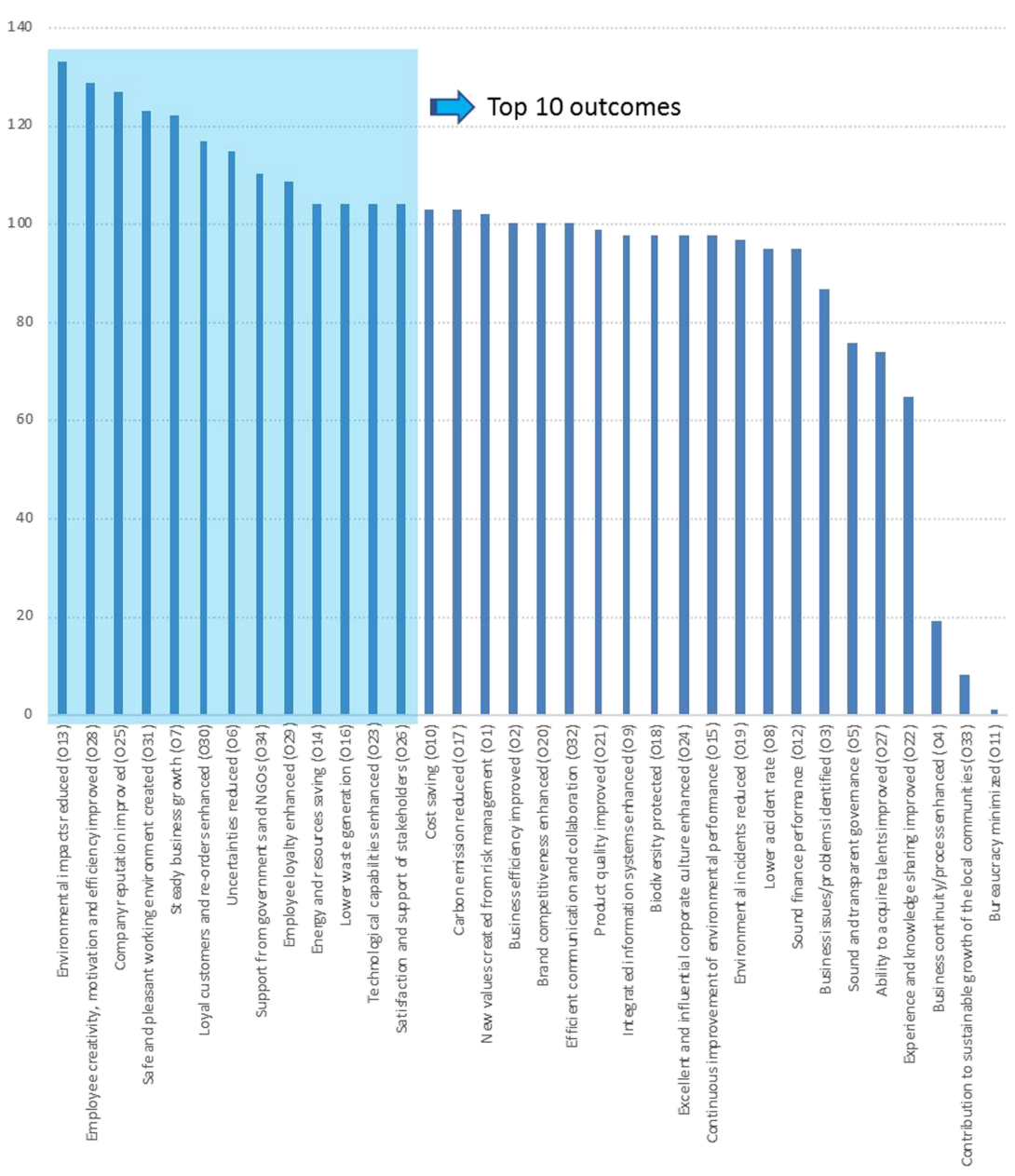

Figure 3. The adjacency matrix was then applied to the SNA software "UCINET" to calculate the centrality degree of each method and outcome. Figure 3 presents the network between methods and outcomes and the top five KAMAO (in green) based on the centrality degree. MEn6, MS10, MG3, MEc4, and MEn7 are the top five key methods, and $\mathrm{O} 13, \mathrm{O} 7, \mathrm{O} 31, \mathrm{O} 25$, and $\mathrm{O} 28$ are the top five key outcomes. A detailed introduction to and discussion of KAMAO are found below.

\section{5 | DISCUSSION}

\section{1 | Top five methods for improving sustainability performance}

In Figure 4, the top five methods for improving international contractors' sustainability performance are identified, including sustainable
FIGURE 3 Adjacency matrices among the top 10 methods and outcomes
MG3 MG4 MEc3 MEc4 MEc5 MS1 MS10 MS13 MEn2 MEn3 MEn6 MEn7 $06 \quad 07 \quad 013 \quad 014 \quad 016 \quad 023 \quad 025026 \quad 028 \quad 029030 \quad 031034$

\begin{tabular}{|c|c|c|c|c|c|c|c|c|c|c|c|c|c|c|c|c|c|c|c|c|c|c|c|c|c|}
\hline & & & & & & & & & & & & & & & & & & & & & & & & & \\
\hline MG3 & & 3 & 3 & 5 & 4 & 4 & 5 & 3 & 4 & 4 & 5 & 4 & 4 & 4 & 3 & 5 & 3 & 3 & 4 & 3 & 5 & 3 & 4 & 4 & 3 \\
\hline MG4 & 3 & & 2 & 4 & 3 & 2 & 4 & 2 & 3 & 3 & 4 & 3 & 3 & 3 & 2 & 4 & 2 & 3 & 4 & 2 & 4 & 2 & 3 & 4 & 3 \\
\hline MEc3 & 3 & 2 & & 3 & 3 & 2 & 4 & 2 & 3 & 3 & 4 & 3 & 3 & 3 & 2 & 4 & 2 & 2 & 4 & 3 & 4 & 2 & 3 & 4 & 3 \\
\hline MEc4 & 5 & 4 & 3 & & 4 & 4 & 5 & 3 & 4 & 4 & 5 & 4 & 3 & 4 & 3 & 5 & 3 & 3 & 4 & 3 & 5 & 3 & 4 & 4 & 3 \\
\hline MEc5 & 4 & 3 & 3 & 4 & & 3 & 4 & 3 & 3 & 3 & 4 & 3 & 3 & 3 & 2 & 5 & 2 & 3 & 4 & 3 & 4 & 2 & 3 & 4 & 3 \\
\hline MS1 & 4 & 2 & 2 & 4 & 3 & & 4 & 2 & 3 & 3 & 4 & 3 & 3 & 3 & 2 & 5 & 2 & 2 & 4 & 3 & 4 & 2 & 3 & 4 & 3 \\
\hline MS10 & 5 & 4 & 4 & 5 & 4 & 4 & & 3 & 4 & 4 & 5 & 4 & 4 & 4 & 3 & 5 & 3 & 3 & 4 & 3 & 5 & 3 & 4 & 4 & 4 \\
\hline MS13 & 3 & 2 & 2 & 3 & 3 & 2 & 3 & & 3 & 3 & 4 & 3 & 3 & 3 & 2 & 4 & 2 & 2 & 4 & 3 & 4 & 3 & 3 & 4 & 3 \\
\hline MEn2 & 4 & 3 & 3 & 4 & 3 & 3 & 4 & 3 & & 3 & 4 & 3 & 3 & 3 & 2 & 5 & 2 & 3 & 4 & 3 & 4 & 3 & 3 & 4 & 3 \\
\hline MEn3 & 4 & 3 & 3 & 4 & 3 & 3 & 4 & 3 & 3 & & 4 & 4 & 3 & 3 & 3 & 5 & 2 & 3 & 4 & 3 & 4 & 2 & 3 & 4 & 3 \\
\hline MEn6 & 5 & 4 & 4 & 5 & 4 & 4 & 5 & 4 & 4 & 4 & & 5 & 4 & 4 & 3 & 5 & 3 & 3 & 4 & 3 & 5 & 4 & 4 & 4 & 4 \\
\hline MEn7 & 4 & 3 & 3 & 4 & 3 & 3 & 4 & 3 & 3 & 4 & 5 & & 4 & 3 & 3 & 5 & 3 & 3 & 4 & 3 & 5 & 3 & 3 & 4 & 3 \\
\hline 06 & 4 & 3 & 3 & 3 & 3 & 3 & 4 & 3 & 3 & 3 & 4 & 4 & & 3 & 2 & 5 & 2 & 3 & 4 & 3 & 4 & 2 & 3 & 4 & 3 \\
\hline 07 & 4 & 3 & 3 & 4 & 3 & 3 & 4 & 3 & 3 & 3 & 4 & 3 & 3 & & 3 & 5 & 3 & 3 & 4 & 3 & 5 & 3 & 3 & 4 & 3 \\
\hline 013 & 3 & 2 & 2 & 3 & 2 & 2 & 3 & 2 & 2 & 3 & 3 & 3 & 2 & 3 & & 4 & 2 & 3 & 4 & 2 & 4 & 2 & 3 & 4 & 3 \\
\hline 014 & 5 & 4 & 4 & 5 & 5 & 5 & 5 & 4 & 5 & 5 & 5 & 5 & 5 & 5 & 4 & & 3 & 3 & 4 & 3 & 5 & 4 & 4 & 4 & 4 \\
\hline 016 & 3 & 2 & 2 & 3 & 2 & 2 & 3 & 2 & 2 & 2 & 3 & 3 & 2 & 3 & 2 & 3 & & 3 & 4 & 2 & 4 & 2 & 3 & 4 & 3 \\
\hline 023 & 3 & 3 & 2 & 3 & 3 & 2 & 3 & 2 & 3 & 3 & 3 & 3 & 3 & 3 & 3 & 3 & 3 & & 4 & 3 & 4 & 2 & 3 & 4 & 3 \\
\hline 025 & 4 & 4 & 4 & 4 & 4 & 4 & 4 & 4 & 4 & 4 & 4 & 4 & 4 & 4 & 4 & 4 & 4 & 4 & & 3 & 5 & 3 & 4 & 4 & 3 \\
\hline 026 & 3 & 2 & 3 & 3 & 3 & 3 & 3 & 3 & 3 & 3 & 3 & 3 & 3 & 3 & 2 & 3 & 2 & 3 & 3 & & 4 & 2 & 3 & 4 & 3 \\
\hline 028 & 5 & 4 & 4 & 5 & 4 & 4 & 5 & 4 & 4 & 4 & 5 & 5 & 4 & 5 & 4 & 5 & 4 & 4 & 5 & 4 & & 3 & 4 & 4 & 4 \\
\hline 029 & 3 & 2 & 2 & 3 & 2 & 2 & 3 & 3 & 3 & 2 & 4 & 3 & 2 & 3 & 2 & 4 & 2 & 2 & 3 & 2 & 3 & & 3 & 4 & 3 \\
\hline 030 & 4 & 3 & 3 & 4 & 3 & 3 & 4 & 3 & 3 & 3 & 4 & 3 & 3 & 3 & 3 & 4 & 3 & 3 & 4 & 3 & 4 & 3 & & 3 & 3 \\
\hline 031 & 4 & 4 & 4 & 4 & 4 & 4 & 4 & 4 & 4 & 4 & 4 & 4 & 4 & 4 & 4 & 4 & 4 & 4 & 4 & 4 & 4 & 4 & 3 & & 3 \\
\hline 034 & 3 & 3 & 3 & 3 & 3 & 3 & 4 & 3 & 3 & 3 & 4 & 3 & 3 & 3 & 3 & 4 & 3 & 3 & 3 & 3 & 4 & 3 & 3 & 3 & \\
\hline
\end{tabular}


and efficient resource, energy, and material use (MEn6), health \& safety management (MS10), stakeholder engagement (MG3), quality management (MEc4), and waste management (MEn7). In-depth analysis of these top five methods is necessary to better understand how they function. Therefore, further discussion was conducted as follows.

\subsection{1 | Sustainable and efficient resource, energy, and material use (MEn6)}

MEn6 is the key method used to promote sustainable and green material use. Research by Shen, Zhang, and Long (2017) underscores that environmental problems in the construction sector stem mainly from the production and use of building materials and natural resources. The selection of building materials also has a considerable influence on building energy performance at the operational stage. Energy consumption in the production of building materials accounts for $33 \%$ of the total energy consumption during the building life cycle. Producing building materials also generates various pollutants (Shen, Zhang, \& Zhang, 2017). According to a report by The Ministry of Environmental Protection of China (2013), the building materials and resources industry accounts for $18 \%$ of the total national industrial pollution emissions.

It is therefore reasonable that most international contractors use this key sustainable method. Take the golden class company Hyundai Engineering \& Construction as an example. It has evaluated the environmental friendliness of materials since 1997 and made the procurement of environment-friendly materials and resources a priority. There are three steps in environment-friendly materials procurement: evaluate the environmental friendliness of the materials, request and order the materials, and monitor the materials. All environmentfriendly materials procured by Hyundai are classified into eight codes (e.g., environmental mark-certified goods and first-rated energy efficiency goods). In addition, it also supports the environmental management of suppliers to encourage the development and production of environment-friendly materials. They are devoted to producing and procuring environment-friendly products through the continuous enhancement of the environment-friendly procurement process by signing the "Voluntary Agreement on Environment-Friendly Procurement" with the Ministry of Environment.

\subsection{2 | Health \& safety management (MS10)}

Jaafar et al. (2018) mentioned that the accident rate in the construction industry is high due to a transient workforce, working at great heights, variable hazards, and very demanding physical and mental requirements. Furthermore, Demirkesen and Arditi (2015) believe that construction is considered a risky endeavor because of the high frequency of work-related fatalities and serious injuries. In referring to the report from the U.S. Bureau of Labor Statistics (2013), even though the construction sector comprises only approximately $5 \%$ of the total workforce, the number of fatal work injuries exceed $17 \%$, and the number of nonfatal injuries and illness total $8 \%$ each, which is $30 \%$ higher than the average of all industries.

With safety management as the first goal of corporate management, Daelim Industrial Co. Ltd. has devoted significant efforts to establish a safety culture. In 2009, Daelim Industrial acquired an international safety and health management system certification for accident prevention and the continuous improvement of its safety and health levels. They have also established a concentrated management policy by analyzing accident cases within their company and in the construction industry over the past 5 years. Lastly, the company used smart phones to help locate and eliminate risk factors regardless of time and place, thus protecting workers from danger by minimizing their exposure time to risk factors.

\subsection{3 | Stakeholder engagement (MG3)}

Yang, Shen, Ho, Drew, and Xue (2011) described the construction project environment as comprising high complexity, high uncertainty, and high equivocality, which makes managing various stakeholders even more difficult. Given the unique nature of construction projects, additional efforts are needed for effective project team management and to balance the interests of various project stakeholders. If the stakeholders are not managed effectively, the probability of successful project completion is reduced due to conflicts among them. Ineffective stakeholder management can also result in dissatisfaction with project outcomes (Manowong \& Ogunlana, 2010). Considering the complex stakeholder environment in the construction industry, communication, coordination, and collaboration among stakeholders are considered important for improving contractors' corporate social responsibility (Lin, Ho, \& Shen, 2018; Xia, Olanipekun, Chen, Xie, \& Liu, 2018).

Take the industry leader Hyundai $E \& C$, for example. It has defined the six major stakeholder groups, namely, government, employees, customers, society, shareholders and investors, and suppliers, which can influence the company either directly or indirectly while operating various communication channels to gather opinions. The company continues to strive to create a better future with internal and external stakeholders through the internalization and advancement of sustainability management. For example, in order to enhance stakeholder engagement, the company conducted a survey with 3,424 internal and external stakeholders through its official website, email, and internal groupware and thus gathered the opinions of customers and stakeholders on Hyundai E\&C's quality and value, their expectation level, complaints, and loyalty.

\subsection{4 | Quality management (MEc4)}

Tan and Abdul-Rahman (2011) found that quality management in construction projects is important for contractors to ensure client satisfaction, establish good relationships with clients, and maintain their long-term competitiveness. Sullivan (2010) found that, compared 
FIGURE 4 The network of methods and outcomes [Colour figure can be viewed at wileyonlinelibrary.com]

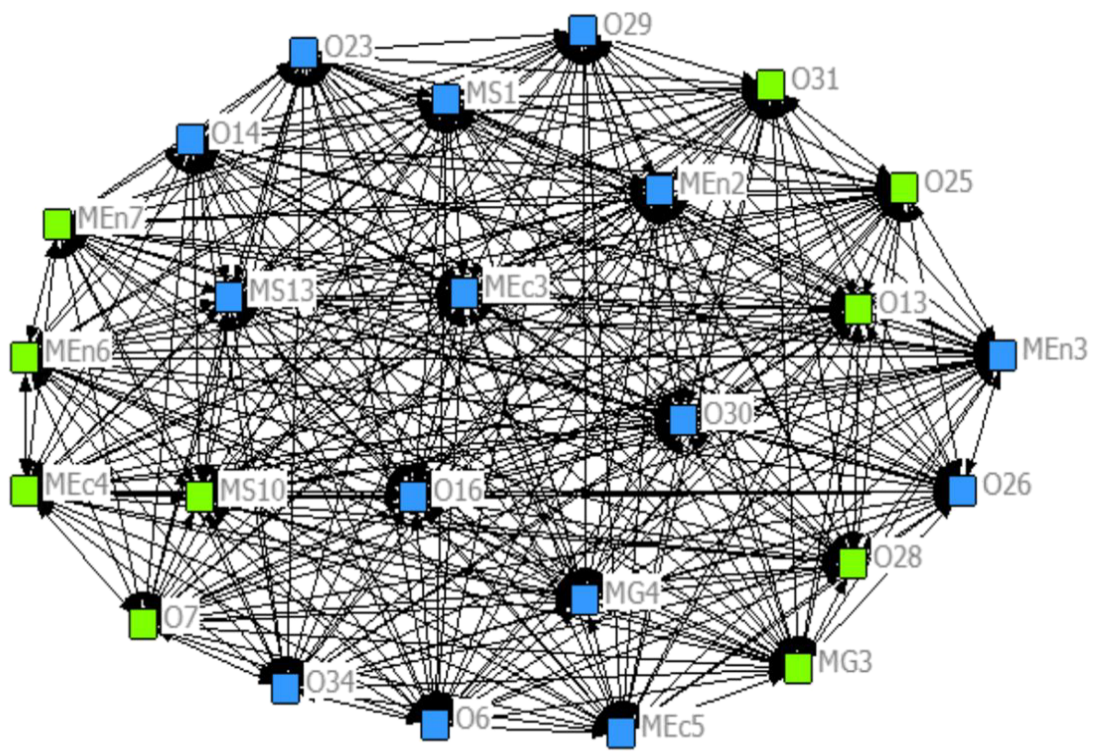

with other industries, the construction industry has trouble increasing productivity using quality management because the productivity per worker in the construction industry has fallen by approximately $25 \%$ over the past 40 years, and the average productivity in all industries has increased by $125 \%$. Hyundai E\&C has made efforts to establish a standardized quality innovation program through process-based thinking and to enhance the capability of responsible personnel. First, they identify and respond to the needs of customers and clients in advance by conducting quality evaluations for all sites every year. They have implemented quality education customized for each site, reflecting each site's various characteristics and needs. In addition, Hyundai $E \& C$ operates an efficient quality management system to effectively respond to internal and external quality risks and to a drastically changing market environment. To prevent the reoccurrence of the same quality-failure cases and to spread success cases, Hyundai E\&C holds regular workshops for suppliers and provides specialized quality education according to work type for quality innovation in order to enhance the value chain.

\subsection{5 | Waste management (MEn7)}

Construction waste is also a common concern at the global level. For example, Ajayi et al. (2017) suggested that the construction industry produces approximately $44 \%$ of landfill waste in the United Kingdom, $29 \%$ in the United States, $44 \%$ in Australia, and an overall global average of approximately $35 \%$. A study conducted by Oko John and Emmanuel Itodo (2013) found that on average, 21-30\% of cost overruns occurred in construction projects due to material wastage. Construction waste does not only consume land but also causes ecological and environmental damage, such as the destruction of a city's natural landscape and soil and water pollution (Coelho \& De Brito, 2012).

With the aim of minimizing waste generation, various methodologies, processes, technologies, and good practices relating to waste management have been incorporated in all of ACCIONA's activities.
For example, the company has a waste management plan that identifies the main types of waste to be dealt with in each project and establishes a management strategy to promote a circular economy model within the company. This strategy proposes certain stages in the waste management hierarchy, including prevention in generation, preparation for reuse, recycling, and other waste-recovery methods.

\subsection{Top five achieved outcomes}

Degree of centrality analysis shows that the top five key achieved outcomes are "environmental impact reduced (O13)," "steady business growth (07)," "safe and pleasant working environment created (O31)," "company reputation enhanced (O25)," and "employee creativity, motivation, and efficiency improved (O28)." The key achieved outcomes are highly correlated to the methods adopted. For example, based on the environmental methods adopted (e.g., MEn6 and MEn7), the environmental impacts are largely reduced and the material energy use has continuously declined. For example, at Hyundai E\&C, the steel consumed amounted to 752,000 tons in 2013 and 670,000 tons in 2015 , down $11 \%$, and concrete consumption was down $8 \%$, sand $87 \%$, coal $24 \%$, and water $47 \%$. Hyundai E\&C's accident rate in 2015 substantially decreased to $0.14 \%$, which is $48 \%$ lower than the $0.27 \%$ in 2014. Medical services at the domestic site contributed to a significant increase in the percentage of employees receiving medical checkups, from $60 \%$ to $94 \%$ of all employees. These substantial performances show that Hyundai E\&C is constantly taking a challenging step forward in the world. The company has received a total of 818 orders (cumulative), reaching USD 120.7 billion in accumulated overseas orders in 2016. The company's revenues, which were KRW 13,938.3 billion in 2013 and KRW 17,387 billion in 2014, drastically increased to KRW 19,122.1 billion in 2015 (consolidated). Its reputation has improved, and the company has received numerous awards: "Global Environment-friendly Construction Company" awarded by the Singapore government, "Asia Today Green Construction" awarded by Asia 
TAB LE 1 Identified key adopted methods and achieved outcomes in three regions

\begin{tabular}{|c|c|c|}
\hline $\begin{array}{l}\text { KAMAO } \\
\text { Region }\end{array}$ & Key adopted methods & Key achieved outcomes \\
\hline Europe & $\begin{array}{l}\text { Stakeholder engagement (MG3) } \\
\text { Quality management (MEc4) } \\
\text { Health \& safety management (MS10) } \\
\text { Sustainable and efficient resource, energy and material use } \\
\quad \text { (MEn6) } \\
\text { Social contribution (MS13) }\end{array}$ & $\begin{array}{l}\text { Steady business growth (O7) } \\
\text { Environmental impacts reduced (O13) } \\
\text { Company reputation improved (O25) } \\
\text { Safe and pleasant working environment created (O31) } \\
\text { Support from governments and NGOs (O34) }\end{array}$ \\
\hline
\end{tabular}

Abbreviation: KAMAO, key adopted methods and achieved outcomes.

Today, "Energy Winner" awarded by Consumers Korea, and "Quality Excellent" awarded by the Building and Construction Authority.

\section{3 | Dynamic trend and regional analysis}

After identifying the KAMAO, the dynamic trends and regional comparison analysis are conducted in this section. A total of 22 companies are classified into three regions according to their geographical locations, including Europe (10 companies and 52 reports), Asia and Oceania (8 companies, 51 reports), and North America (4 companies, 30 reports). Asia and Oceania are integrated because there is only one company in Oceania and it has very few reports. Similar to the procedures above, the KAMAO in different continents are identified and presented in Table 1.

As shown in Table 1, it is interesting to note that most of the key methods and outcomes on different continents are similar. For example, most continents adopt methods (MEn6, MG3, MEc4, MS10) and achieved the outcomes $(\mathrm{O} 13, \mathrm{O} 25, \mathrm{O} 7, \mathrm{O} 31)$ with slight ranking differences, which indicates that geographical location is not a determining factor of key methods and outcomes. This is primarily due to two reasons. First, most of the companies are top international contractors, meaning they do not only have projects in their home countries but also operate a large number of international construction projects. They compete in the international market with similar requirements for sustainable methods and outcomes. Take Hyundai E\&C, for example, benefitting from its advanced technology and good reputation, it has 27 overseas branches and 77 construction sites in various countries across the world, such as the United Kingdom, Algeria, Chile, Qatar, and China, with an annual revenue exceeding 10 billion dollars, accounting for $58 \%$ of its total income. Another example is the worldleading Spanish construction company ACCIONA, which also has projects in over 40 countries (e.g., the United Kingdom, Algeria, Chile, Qatar, and (anada) on five continents; its annual revenue amounts to 3,468 million euros, or $53 \%$ of its total income. The second reason is that most of the key methods and outcomes, such as MG3, MEc4, $\mathrm{O} 13$, and $\mathrm{O} 25$, are comprehensive and have been shown to be the common concerns and goals of construction companies. Although their detailed strategies and outcomes may differ slightly, the general directions should be the same among various companies.

To analyze the dynamic trend of the KAMAO, all companies' reports were also analyzed annually; the results of the SNA are shown in Figure 5.

It can be seen from Figure 5 that the KAMAO changed only slightly during the study period of 2010-2016. Most key adopted methods are the same, with slight differences in ranking (e.g., Men6,
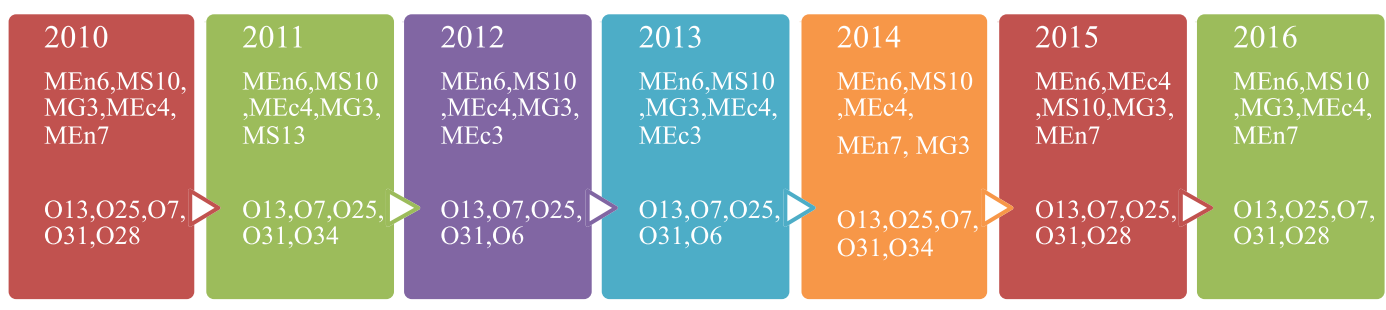

FIGURE 5 The dynamic trend of key adopted methods and achieved outcomes [Colour figure can be viewed at wileyonlinelibrary.com] 
MS10, MEc4, and MG3). This is mainly because these methods have been assessed by these sustainability leaders and proved to be comprehensively effective in promoting corporate sustainability in the construction sector. It is therefore reasonable for companies to use the same methods annually. As mentioned earlier, most outcomes are connected with methods, which indicates that most outcomes should be almost the same as well (e.g., O7, O13, O25, O31). In addition, it is worth noting that most of the KAMAO of the regional and dynamic trend analysis are the same as the overall KAMAO analysis, which is considered solid support for the reliability of the results of overall KAMAO analysis.

\section{6 | CONCLUSIONS}

This study identified the KAMAO from the best sustainable construction corporations using content analysis and SNA. The top five key adopted methods are "sustainable and efficient resource and material use," "health \& safety management," "stakeholder engagement," "quality management," and "waste management." The top five key achieved outcomes are "environmental impact reduced," "steady business growth," "safe and pleasant working environment created," "company reputation enhanced," and "employee creativity, motivation, and efficiency improved." In addition, a regional analysis and a dynamic trend analysis have been carried out, and results show that the key methods and outcomes are similar for sustainability leaders in the construction sector when temporal and geographical factors are taken into account.

With an increasing demand for the sustainable development of the construction industry, sustainability performance has become an important competitive advantage for international contractors competing in the international market. Improving sustainability performance will enhance international contractors' competitiveness and help them win more contracts. The findings in this study can help international contractors achieve a better understanding of the top sustainable methods adopted by sustainability leaders in the construction sector and related outcomes achieved and provide them with a useful reference and guide for developing their future sustainability strategies. In this study, only 22 sustainability leaders in the construction sector were selected for analysis. In future studies, nonsustainability leaders in the construction sector could be examined to explore further methods of effectively improving sustainability performance. In addition, the KAMAO for small-to-medium-sized contractors could also be examined.

\section{ACKNOWLEDGMENTS}

This research was supported by the start-up fund for new staff of the School of Engineering, RMIT University, Australia.

\section{ORCID}

Yongtao Tan (ID https://orcid.org/0000-0001-7321-4251 Chenyang Shuai (D) https://orcid.org/0000-0001-8789-0111 Liyin Shen (iD https://orcid.org/0000-0003-3158-9762

\section{REFERENCES}

Ajayi, S. O., Oyedele, L. O., Bilal, M., Akinade, O. O., Alaka, H. A., \& Owolabi, H. A. (2017). Critical management practices influencing onsite waste minimization in construction projects. Waste Management, 59, 330-339. https://doi.org/10.1016/j.wasman.2016.10.040

Alrazi, B., De Villiers, C., \& Van Staden, C. J. (2015). A comprehensive literature review on, and the construction of a framework for, environmental legitimacy, accountability and proactivity. Journal of Cleaner Production, 102, 44-57.

Arena, C., Bozzolan, S., \& Michelon, G. (2015). Environmental reporting: Transparency to stakeholders or stakeholder manipulation? An analysis of disclosure tone and the role of the board of directors. Corporate Social Responsibility and Environmental Management, 22(6), 346-361.

Arrive, J. T., \& Feng, M. (2018). Corporate social responsibility disclosure: Evidence from BRICS nations. Corporate Social Responsibility and Environmental Management, 25(5), 920-927.

Bansal, P. (2005). Evolving sustainably: A longitudinal study of corporate sustainable development. Strategic Management Journal, 26(3), 197-218.

Baumgartner, R. J., \& Ebner, D. (2010). Corporate sustainability strategies: sustainability profiles and maturity levels. Sustainable Development, 18(2), 76-89.

Baumgartner, R. J., \& Rauter, R. (2017). Strategic perspectives of corporate sustainability management to develop a sustainable organization. Journal of Cleaner Production, 140, 81-92.

Benavides-Velasco, C. A., Quintana-García, C., \& Marchante-Lara, M. (2014). Total quality management, corporate social responsibility and performance in the hotel industry. International Journal of Hospitality Management, 41, 77-87.

Benn, S., Edwards, M., \& Williams, T. (2014). Organizational change for corporate sustainability. London: Routledge.

Berelson, B. (1952). Content analysis in communication research. Glencoe III: Free Press.

Berkowitz, D., Ma, H., \& Nishioka, S. (2017). Recasting the iron rice bowl: The reform of China's state-owned enterprises. Review of Economics and Statistics, 99(4), 735-747.

Bierwerth, M., Schwens, C., Isidor, R., \& Kabst, R. (2015). Corporate entrepreneurship and performance: A meta-analysis. Small Business Economics, 45(2), 255-278.

Boiral, O., \& Heras-Saizarbitoria, I. (2017). Best practices for corporate commitment to biodiversity: An organizing framework from GRI reports. Environmental Science \& Policy, 77, 77-85.

Borio, C. E. V., \& Lowe, P. W. (2002). Asset prices, financial and monetary stability: Exploring the nexus. BIS Working Paper, No.114.

Bureau of Labor Statistics. (2013). Numbers of nonfatal occupational injuries and illnesses by case type and ownership. http://www.bls.gov/ news.release/osh.t02.htm.

Burke, R. D., Parrish, K., \& El Asmar, M. (2018). Environmental product declarations: Use in the architectural and engineering design process to support sustainable construction. Journal of Construction Engineering and Management, 144(5), 04018026.

Butler, T. (2011). Compliance with institutional imperatives on environmental sustainability: Building theory on the role of Green IS. The Journal of Strategic Information Systems, 20(1), 6-26.

Camilleri, M. A. (2015). Valuing stakeholder engagement and sustainability reporting. Corporate Reputation Review, 18(3), 210-222.

Chen, J., Shen, L., Song, X., Shi, Q., \& Li, S. (2017). An empirical study on the $\mathrm{CO} 2$ emissions in the Chinese construction industry. Journal of Cleaner Production, 168, 645-654.

Coelho, A., \& De Brito, J. (2012). Influence of construction and demolition waste management on the environmental impact of buildings. Waste Management, 32(3), 532-541.

Demirkesen, S., \& Arditi, D. (2015). Construction safety personnel's perceptions of safety training practices. International Journal of Project Management, 33(5), 1160-1169. 
den Hond, F., de Bakker, F. G. A., \& Doh, J. (2015). What prompts companies to collaboration with NGOs? Recent evidence from the Netherlands. Business \& Society, 54(2), 187-228.

Frias-Aceituno, J. V., Rodriguez-Ariza, L., \& Garcia-Sanchez, I. M. (2013). The role of the board in the dissemination of integrated corporate social reporting. Corporate Social Responsibility and Environmental Management, 20(4), 219-233.

Fritsch, M., \& Kauffeld-Monz, M. (2010). The impact of network structure on knowledge transfer: An application of social network analysis in the context of regional innovation networks. The Annals of Regional Science, 44(1), 21-38. https://doi.org/10.1007/s00168-0080245-8

Guo, S., Ding, L., Zhang, Y., Skibniewski, M. J., \& Liang, K. (2019). Hybrid recommendation approach for behavior modification in the Chinese construction industry. Journal of Construction Engineering and Management, 145(6), 04019035. https://doi.org/10.1061/(ASCE)CO.19437862.0001665

Hellweg, S., \& i Canals, L.M. (2014). Emerging approaches, challenges and opportunities in life cycle assessment. Science, 344(6188), 1109-1113. https://doi.org/10.1126/science.1248361

Jaafar, M. H., Arifin, K., Aiyub, K., Razman, M. R., Ishak, M. I. S., \& Samsurijan, M. S. (2018). Occupational safety and health management in the construction industry: A review. International Journal of Occupational Safety and Ergonomics, 24(4), 493-506.

Järlström, M., Saru, E., \& Vanhala, S. (2018). Sustainable human resource management with salience of stakeholders: $A$ top management perspective. Journal of Business Ethics, 152(3), 703-724.

Jenkins, S., Bhanugopan, R., \& Lockhart, P. (2016). A framework for optimizing work-life balance practices in Australia: Perceived options for employee support. Journal of Employment Counseling, 53(3), 112-129.

Jerónimo Silvestre, W., Antunes, P., Amaro, A., \& Leal Filho, W. (2015). Assessment of corporate sustainability: Study of hybrid relations using Hybrid Bottom Line model. International Journal of Sustainable Development and World Ecology, 22(4), 302-312.

Kibert, C. J. (1994). Establishing principles and a model for sustainable construction. Proceedings of the first international conference on sustainable construction. Tampa Florida. November, pp. 6-9.

Kristina, Y., Ahmad, S., \& Pratama, A. Y. (2014). Achieving environmental excellence: Through 3R waste management. Proceedings of the 38th Annual Convention of the Indonesian Petroleum Association 2014: Strengthening Partnerships to Enhance Indonesia's Energy Resilience and Global Competitiveness. Jakarta, Indonesia.

Kuratko, D. F., Hornsby, J. S., \& Covin, J. G. (2014). Diagnosing a firm's internal environment for corporate entrepreneurship. Business Horizons, 57(1), 37-47.

Lee, S. Y., Park, Y. S., \& Klassen, R. D. (2015). Market responses to firms' voluntary climate change information disclosure and carbon communication. Corporate Social Responsibility and Environmental Management, 22(1), 1-12.

Leonard, J. C., \& Wilkinson, T. J. (2014). Market and bureaucracy costs: The moderating effect of information technology. Journal of Management Information and Decision Sciences, 17(2), 81-97.

Leonidou, L. C., Christodoulides, P., \& Thwaites, D. (2016). External determinants and financial outcomes of an eco-friendly orientation in smaller manufacturing firms. Journal of Small Business Management, 54(1), 5-25.

Lin, X., Ho, C. M., \& Shen, G. Q. (2018). Research on corporate social responsibility in the construction context: A critical review and future directions. International Journal of Construction Management, 18(5), 394-404.

Linnenluecke, M. K., \& Griffiths, A. (2010). Corporate sustainability and organizational culture. Journal of World Business, 45(4), 357-366.

Lo, S. F., \& Sheu, H. J. (2007). Is corporate sustainability a value-increasing strategy for business? Corporate Governance: An International Review, 15(2), 345-358.
Loughead, T. M., Fransen, K., Van Puyenbroeck, S., Hoffmann, M. D., De Cuyper, B., Vanbeselaere, N., \& Boen, F. (2016). An examination of the relationship between athlete leadership and cohesion using social network analysis. Journal of Sports Sciences, 34(21), 2063-2073.

Lozano, R. (2015). A holistic perspective on corporate sustainability drivers. Corporate Social Responsibility and Environmental Management, 22(1), 32-44.

Maas, K., Schaltegger, S., \& Crutzen, N. (2016). Integrating corporate sustainability assessment, management accounting, control, and reporting. Journal of Cleaner Production, 136, 237-248.

Manowong, E., \& Ogunlana, S. (2010). Strategies and tactics for managing construction stakeholders. In E. Manowong \& S. Ogunlana (Eds.), Construction Stakeholder Management (pp. 121-137). Oxford: WileyBlackwell.

Maxwell, R., \& Knox, S. (2009). Motivating employees to" live the brand": A comparative case study of employer brand attractiveness within the firm. Journal of Marketing Management, 25(9-10), 893-907.

Methven O'Brien, C., \& Dhanarajan, S. (2016). The corporate responsibility to respect human rights: A status review. Accounting, Auditing \& Accountability Journal, 29(4), 542-567.

Money, K., Hillenbrand, C., Hunter, I., \& Money, A. G. (2012). Modelling bidirectional research: A fresh approach to stakeholder theory. Journal of Strategy and Management, 5(1), 5-24.

Muhammad, N., Scrimgeour, F., Reddy, K., \& Abdin, S. (2016). Emission indices for hazardous substances: An alternative measure of corporate environmental performance. Corporate Social Responsibility and Environmental Management, 23(1), 15-26.

National Bureau of Statistics of China (NBSC). (2015). China Statistics Yearbook. Beijing: China Statistics Press.

Nielsen, S. B., Sarasoja, A.-L., \& Galamba, K. R. (2016). Sustainability in facilities management: An overview of current research. Facilities, 34(9/10), 535-563.

Nightingale, D. J., \& Srinivasan, J. (2011). Beyond the lean revolution: Achieving successful and sustainable enterprise transformation. New York: American Management Association.

Oko John, A., \& Emmanuel Itodo, D. (2013). Professionals' views of material wastage on construction sites and cost overruns. Organization, Technology \& Management in Construction: An International Journal, 5(1), 747-757.

Ortiz-de-Mandojana, N., Aguilera-Caracuel, J., \& Morales-Raya, M. (2016). Corporate governance and environmental sustainability: The moderating role of the national institutional context. Corporate Social Responsibility and Environmental Management, 23(3), 150-164.

Papaoikonomou, E., Ryan, G., \& Ginieis, M. (2011). Towards a holistic approach of the attitude behaviour gap in ethical consumer behaviours: Empirical evidence from Spain. International Advances in Economic Research, 17(1), 77-88.

Patchell, J., \& Hayter, R. (2013). How big business can save the climate: Multinational corporations can succeed where governments have failed. Foreign Affairs, 92(5), 17-22.

Pearce, D. W. (2003). Environment and business: Socially responsible but privately profitable? In J. Hirst (Ed.), The Challenge of Change: Fifty Years of Business Economics (pp. 54-65). London: Profile Books.

Pedersen, E. R. G., Gwozdz, W., \& Hvass, K. K. (2018). Exploring the relationship between business model innovation, corporate sustainability, and organisational values within the fashion industry. Journal of Business Ethics, 149(2), 267-284.

Peloza, J., \& Shang, J. (2011). How can corporate social responsibility activities create value for stakeholders? A systematic review. Journal of the Academy of Marketing Science, 39(1), 117-135.

Rao, P., \& Holt, D. (2005). Do green supply chains lead to competitiveness and economic performance? International Journal of Operations \& Production Management, 25(9), 898-916.

Rego, A., e Cunha, M. P., \& Polónia, D. (2017). Corporate sustainability: A view from the top. Journal of Business Ethics, 143(1), 133-157. 
Rezaee, Z. (2009). Corporate governance and ethics. New York: John Wiley $\&$ Sons.

Robinson, H. S., Anumba, C. J., Carrillo, P. M., \& Al-Ghassani, A. M. (2006). STEPS: A knowledge management maturity roadmap for corporate sustainability. Business Process Management Journal, 12(6), 793-808.

Rodger, J. A., \& George, J. A. (2017). Triple bottom line accounting for optimizing natural gas sustainability: A statistical linear programming fuzzy ILOWA optimized sustainment model approach to reducing supply chain global cybersecurity vulnerability through information and communications technology. Journal of Cleaner Production, 142, 1931-1949.

Schaltegger, S., \& Burritt, R. (2018). Business cases and corporate engagement with sustainability: Differentiating ethical motivations. Journal of Business Ethics, 147(2), 241-259.

Shen, L., Zhang, Z., \& Long, Z. (2017). Significant barriers to green procurement in real estate development. Resources, Conservation and Recycling, 116, 160-168.

Shen, L., Zhang, Z., \& Zhang, X. (2017). Key factors affecting green procurement in real estate development: A China study. Journal of Cleaner Production, 153, 372-383.

Shen, L.-Y., Ochoa, J. J., Shah, M. N., \& Zhang, X. (2011). The application of urban sustainability indicators-A comparison between various practices. Habitat International, 35(1), 17-29.

Sherwin, M. D., Medal, H., \& Lapp, S. A. (2016). Proactive cost-effective identification and mitigation of supply delay risks in a low volume high value supply chain using fault-tree analysis. International Journal of Production Economics, 175, 153-163.

Shi, Q., Chen, J., \& Shen, L. (2017). Driving factors of the changes in the carbon emissions in the Chinese construction industry. Journal of Cleaner Production, 166, 615-627.

Subramaniam, N., Kansal, M., \& Babu, S. (2017). Governance of mandated corporate social responsibility: Evidence from Indian governmentowned firms. Journal of Business Ethics, 143(3), 543-563.

Sullivan, K. T. (2010). Quality management programs in the construction industry: Best value compared with other methodologies. Journal of Management in Engineering, 27(4), 210-219.

Tan, C. K. \& Abdul-Rahman, H. (2011). Study of quality management in construction projects. Chinese Business Review, 10(7), 542-552.

Tan, Y., Ochoa, J. J., Langston, C., \& Shen, L. (2015). An empirical study on the relationship between sustainability performance and business competitiveness of international construction contractors. Journal of Cleaner Production, 93, 273-278.

Tan, Y., Shen, L., \& Yao, H. (2011). Sustainable construction practice and contractors' competitiveness: A preliminary study. Habitat International, 35(2), 225-230.
Tan, Y., Xu, H., Jiao, L., Ochoa, J. J., \& Shen, L. (2017). A study of best practices in promoting sustainable urbanization in China. Journal of Environmental Management, 193, 8-18. https://doi.org/10.1016/j.jenvman. 2017.01.058

Tantalo, C., \& Priem, R. L. (2016). Value creation through stakeholder synergy. Strategic Management Journal, 37(2), 314-329.

Tembo-Silungwe, C. K., \& Khatleli, N. (2018). Identification of enablers and constraints of risk allocation using structuration theory in the construction industry. Journal of Construction Engineering and Management, 144(5), 04018021.

The Ministry of Environmental Protection of China (2013). China Statistical Yearbook on Environment. Beijing: China Statistics Press.

U.S. Environmental Protection Agency. (2009). Buildings and their impact on the environment: A statistical summary. Available at http://www. epa.gov/greenbuilding/pubs/gbstats.pdf.

Welford, R. (2016). Corporate environmental management 2: Culture and organization (e-book). London: Routledge.

Whitehead, J. (2017). Prioritizing sustainability indicators: Using materiality analysis to guide sustainability assessment and strategy. Business Strategy and the Environment, 26(3), 399-412.

Wu, Y., Chau, K. W., Lu, W., Shen, L., Shuai, C., \& Chen, J. (2018). Decoupling relationship between economic output and carbon emission in the Chinese construction industry. Environmental Impact Assessment Review, 71, 60-69.

Xia, B., Olanipekun, A., Chen, Q., Xie, L., \& Liu, Y. (2018). Conceptualising the state of the art of corporate social responsibility (CSR) in the construction industry and its nexus to sustainable development. Journal of Cleaner Production, 195, 340-353.

Yang, J., Shen, G. Q., Ho, M., Drew, D. S., \& Xue, X. (2011). Stakeholder management in construction: An empirical study to address research gaps in previous studies. International Journal of Project Management, 29(7), 900-910.

Zhu, Q., Geng, Y., \& Lai, K.-h. (2010). Circular economy practices among Chinese manufacturers varying in environmental-oriented supply chain cooperation and the performance implications. Journal of Environmental Management, 91(6), 1324-1331. https://doi.org/10.1016/j. jenvman.2010.02.013

How to cite this article: Tan Y, Shuai C, Shen L, Hou L, Zhang G. A study of sustainable practices in the sustainability leadership of international contractors. Sustainable Development. 2020;28:697710. https://doi.org/10.1002/sd.2020 


\section{APPENDIX}

TABLE A1 The list of methods used for improving corporate sustainability performance

\begin{tabular}{|c|c|c|}
\hline Dimension & Methods (code) & Supporting references \\
\hline \multirow[t]{14}{*}{ Governance } & Promoting entrepreneurship (MG1) & Bierwerth et al. (2015) \\
\hline & Management systems certification (MG2) & Jerónimo Silvestre et al. (2015) \\
\hline & Stakeholder engagement (MG3) & Camilleri (2015) \\
\hline & Materiality analysis (MG4) & Whitehead (2017) \\
\hline & Ongoing commitment to innovation and R\&D (MG5) & Frias-Aceituno, Rodriguez-Ariza, and Garcia-Sanchez (2013) \\
\hline & Dissemination and leadership (MG6) & Loughead et al. (2016) \\
\hline & Transparent information disclosure (MG7) & Money, Hillenbrand, Hunter, and Money (2012) \\
\hline & Knowledge management (MG8) & Robinson et al. (2006) \\
\hline & $\begin{array}{l}\text { Efficiency, integrity and transparent corporate governance } \\
\text { (MG9) }\end{array}$ & Rezaee (2009) \\
\hline & Compliance promotion (MG10) & Butler (2011) \\
\hline & Business continuity plans (MG11) & Pedersen, Gwozdz, and Hvass (2018) \\
\hline & Strengthen information security (MG12) & Rodger and George (2017) \\
\hline & Intellectual property management (MG13) & Nielsen, Sarasoja, and Galamba (2016) \\
\hline & Corporate culture with shared values (MG14) & Linnenluecke and Griffiths (2010) \\
\hline \multirow[t]{12}{*}{ Economy } & Responsibilities and minimizing bureaucracy (MEc1) & Subramaniam, Kansal, and Babu (2017) \\
\hline & Sustainability management of supply chain (MEc2) & Rao and Holt (2005) \\
\hline & Risk management (MEc3) & Lozano (2015) \\
\hline & Quality management (MEc4) & Sullivan (2010) \\
\hline & Concern with customer satisfaction (MEc5) & Peloza and Shang (2011) \\
\hline & Strengthening financial and operational stability (MEc6) & Borio and Lowe (2002) \\
\hline & Providing sustainable production and service (MEc7) & Papaoikonomou, Ryan, and Ginieis (2011) \\
\hline & Creation of long-term values (MEc8) & Tantalo and Priem (2016) \\
\hline & Lean overhead (MEc9) & Nightingale and Srinivasan (2011) \\
\hline & Business portfolio optimization (MEc10) & Lo and Sheu (2007) \\
\hline & Proactive cost management (MEc11) & Sherwin et al. (2016) \\
\hline & Strengthening core business leadership (MEc12) & Benn, Edwards, and Williams (2014) \\
\hline \multirow[t]{14}{*}{ Social } & Ethical management (MS1) & Schaltegger and Burritt (2018) \\
\hline & Respect of human rights (MS2) & Methven O'Brien and Dhanarajan (2016) \\
\hline & Mobilizing the employees (MS3) & Rego, e Cunha, and Polónia (2017) \\
\hline & Improving working conditions (MS4) & Baumgartner and Rauter (2017) \\
\hline & Culture of trust, communication and cooperation (MS5) & Rego et al. (2017) \\
\hline & Diversity and equal treatment of employees (MS6) & Järlström, Saru, and Vanhala (2018) \\
\hline & Performance management (MS7) & Maas, Schaltegger, and Crutzen (2016) \\
\hline & Attractive employee remuneration and welfare (MS8) & Maxwell and Knox (2009) \\
\hline & Sharing the benefits with employees (MS9) & Maxwell and Knox (2009) \\
\hline & Health \& safety management (MS10) & Baumgartner and Ebner (2010) \\
\hline & Work-life balance of employees (MS11) & Jenkins et al. (2016) \\
\hline & Win-win cooperation with suppliers (MS12) & Zhu, Geng, and Lai (2010) \\
\hline & Social contribution (MS13) & Arrive and Feng (2018) \\
\hline & Cooperation and advisory projects with NGOs (MS14) & den Hond et al. (2015) \\
\hline \multirow[t]{3}{*}{ Environment } & Environmental management system (MEn1) & Welford (2016) \\
\hline & Climate changes response (MEn2) & Lee et al. (2015) \\
\hline & Eco-friendly technologies (MEn3) & Leonidou, Christodoulides, and Thwaites (2016) \\
\hline
\end{tabular}


TABLE A1 (Continued)

\begin{tabular}{lll} 
Dimension & Methods (code) & Supporting references \\
\hline Environmental accounting (MEn4) & Alrazi, De Villiers, and Van Staden (2015) \\
Engage in environmental projects (MEn5) & Lozano (2015) \\
$\begin{array}{l}\text { Sustainable and efficient resource, energy and material use } \\
\text { (MEn6) }\end{array}$ & $\begin{array}{c}\text { Ortiz-de-Mandojana, Aguilera-Caracuel, and Morales-Raya } \\
(2016)\end{array}$ \\
Waste management (MEn7) & Kristina et al. (2014) \\
Protection of biodiversity (MEn8) & Boiral and Heras-Saizarbitoria (2017) \\
Implementation of life cycle assessments (MEn9) & Hellweg, and i Canals, L.M. (2014) \\
Reporting environmental incidents (MEn10) & Arena, Bozzolan, and Michelon (2015) \\
Hazardous substance management (MEn11) & Muhammad, Scrimgeour, Reddy, and Abdin (2016)
\end{tabular}

\section{APPENDIX}

TAB LE B1 The list of outcomes achieved through implementing sustainable practices

\section{Outcomes}

New values created from risk management (O1)

Business efficiency improved (O2)

Business issues/problems identified (O3)

Business continuity/process enhanced (O4)

Sound and transparent governance (O5)

Uncertainties reduced (O6)

Steady business growth $(\mathrm{O} 7)$

Lower accident rate (O8)

Integrated information systems enhanced (O9)

Cost saving (O10)

Bureaucracy minimized (O11)

Sound financial performance (O12)

Environmental impacts reduced (O13)

Energy and resources saving (O14)

Continuous improvement of environmental performance (O15)

Lower waste generation (O16)

Carbon emission reduced (O17)

Biodiversity protected (O18)

Environmental incidents reduced (O19)

Brand competitiveness enhanced (O20)

Product quality improved (O21)

Experience and knowledge sharing improved (O22)

Technological capabilities enhanced (O23)

Excellent and influential corporate culture enhanced (O24)

Company reputation improved (O25)

Satisfaction and support of stakeholders (O26)

Ability to acquire talents improved (O27)

Employee creativity, motivation and efficiency improved (O28)

Employee loyalty enhanced (O29)

Loyal customers and reorders enhanced (O30)

\section{Supporting references}

Lozano (2015)

Subramaniam et al. (2017); Camilleri (2015)

Whitehead (2017)

Camilleri (2015)

Rezaee (2009); Money et al. (2012)

Bansal (2005); Patchell and Hayter (2013)

Peloza and Shang (2011); Camilleri (2015)

Nielsen et al. (2016)

Money et al. (2012); Rodger and George (2017); Arena et al. (2015)

Sherwin et al. (2016); Patchell and Hayter (2013)

Leonard and Wilkinson (2014)

Lo and Sheu (2007)

Leonidou et al. (2016); Boiral and Heras-Saizarbitoria (2017)

Ortiz-de-Mandojana et al. (2016)

Lee et al. (2015); Kristina et al. (2014); Ortiz-de-Mandojana et al. (2016)

Kristina et al. (2014)

Lee et al. (2015)

Boiral and Heras-Saizarbitoria (2017)

Arena et al. (2015)

den Hond et al. (2015); Ortiz-de-Mandojana et al. (2016)

Benavides-Velasco, Quintana-García, and Marchante-Lara (2014)

Robinson et al. (2006)

Patchell and Hayter (2013); Leonidou et al. (2016)

Rego et al. (2017); Methven O'Brien and Dhanarajan (2016)

Arrive and Feng (2018); Kuratko, Hornsby, and Covin (2014); Lee et al. (2015)

Camilleri (2015); Baumgartner and Ebner (2010)

Jenkins et al. (2016)

Baumgartner and Rauter (2017); Jenkins et al. (2016)

Maxwell and Knox (2009); Järlström et al. (2018)

Peloza and Shang (2011); Papaoikonomou et al. (2011) 
TABLE B1 (Continued)

\section{Outcomes}

Safe and pleasant working environment created (O31)

Efficient communication and collaboration (O32)

Contribution to sustainable growth of the local communities (O33)

Support from governments and NGOs (O34)

\section{Supporting references}

Baumgartner and Ebner (2010)

Methven O'Brien and Dhanarajan (2016)

Arrive and Feng (2018); Lozano (2015)

den Hond et al. (2015)

\section{APPENDIX}

TAB LE C1 The 22 sustainability leaders in the construction sector

\begin{tabular}{|c|c|c|}
\hline No. & Construction company & Country \\
\hline 1 & Hyundai Engineering \& Construction & South Korea \\
\hline 2 & Daelim Industrial Co. Ltd. & South Korea \\
\hline 3 & GS Engineering \& Construction Corp & South Korea \\
\hline 4 & Samsung Engineering Co. Ltd. & South Korea \\
\hline 5 & $\begin{array}{l}\text { Doosan Heavy Industries \& Construction } \\
\text { Co. Ltd. }\end{array}$ & South Korea \\
\hline 6 & ACCIONA SA & Spain \\
\hline 7 & Fomento de Construcciones y Contratas & Spain \\
\hline 8 & (Grupo) Ferrovial SA & Spain \\
\hline 9 & $\begin{array}{l}\text { ACS Actividades de Construccion y } \\
\text { Servicios SA }\end{array}$ & Spain \\
\hline 10 & Jacobs Engineering Group Inc & USA \\
\hline 11 & Insituform Technologies Inc & USA \\
\hline 12 & Fluor Corp & USA \\
\hline 13 & Balfour Beatty PLC & UK \\
\hline 14 & Amec PLC & UK \\
\hline 15 & Taisei Corp & Japan \\
\hline 16 & Kajima Corp & Japan \\
\hline 17 & Skanska AB & Sweden \\
\hline 18 & SNC-Lavalin Group Inc & Canada \\
\hline 19 & CIMIC Group Ltd. (Australia) & Australia \\
\hline 20 & Hochtief AG & Germany \\
\hline 21 & Outotec OYJ & Finland \\
\hline 22 & Vinci SA & France \\
\hline
\end{tabular}

